\title{
Inflammation scores as prognostic biomarkers in small cell lung cancer: a systematic review and meta-analysis
}

\author{
Anne Winther-Larsen ${ }^{1}$, Ninna Aggerholm-Pedersen ${ }^{2}$ and Birgitte Sandfeld-Paulsen ${ }^{3^{*}}$ (D)
}

\begin{abstract}
Background: Inflammation scores based on general inflammation markers as leucocyte count or C-reactive protein have been evaluated as prognostic markers of inferior survival in several cancers. In small cell lung cancer (SCLC), however, inflammation scores are less studied. In the present study, we set out to perform a systematic review and meta-analysis investigating reported associations between inflammation scores and overall survival (OS) in SCLC.

Methods: A literature search was performed in PubMed, Embase, Scopus, and Web of Science following the Preferred Reporting Items for Systematic and Meta-Analyses (PRISMA) guidelines. Of the identified publications, only studies in English containing original data evaluating inflammation scores as a prognostic factor in SCLC patients were included. Hazard ratios (HRs) for OS were pooled in a random-effects model.

Results: In total, 33 articles were included evaluating eight different inflammation scores in 7762 SCLC patients. Seven of the identified scores were based on leucocyte count. Neutrophil-to-lymphocyte ratio (NLR) and platelet-tolymphocyte (PLR) ratio were the most frequently evaluated scores (NLR: $n=23$; PLR: $n=22$ ). For NLR, a metaanalysis including 16 studies demonstrated that patients with a high NLR had a significantly shorter OS compared to patients with a low NLR (pooled HR $=1.39(95 \% \mathrm{Cl}, 1.23-1.56)$ ). For PLR, an association with survival could not be confirmed in a meta-analysis performed based on eight studies (pooled $\mathrm{HR}=1.20$ (95\% Cl, 0.96-1.51)).

Conclusions: This review identifies that inflammation scores based on general inflammation markers have some potential as prognostic biomarkers in SCLC. The meta-analyses indicated that NLR is associated with inferior OS, whereas an association between PLR and OS could not be confirmed. Thus, NLR could be a useful biomarker of OS in SCLC patients.

Systematic review registration: The protocol for the study was submitted to the PROSPERO database (registration number CRD42020188553).

Keywords: Small cell lung cancer, Inflammation scores, Neutrophil-to-lymphocyte ratio, Platelet-to-lymphocyte ratio, Glasgow prognostic score, Survival, Meta-analysis
\end{abstract}

\footnotetext{
*Correspondence: birgne@rm.dk

${ }^{3}$ Department of Clinical Biochemistry, Aarhus University Hospital, Palle Juul-Jensens Boulevard 99, 8200 Aarhus N, Denmark

Full list of author information is available at the end of the article
}

(c) The Author(s). 2021 Open Access This article is licensed under a Creative Commons Attribution 4.0 International License, which permits use, sharing, adaptation, distribution and reproduction in any medium or format, as long as you give appropriate credit to the original author(s) and the source, provide a link to the Creative Commons licence, and indicate if changes were made. The images or other third party material in this article are included in the article's Creative Commons licence, unless indicated otherwise in a credit line to the material. If material is not included in the article's Creative Commons licence and your intended use is not permitted by statutory regulation or exceeds the permitted use, you will need to obtain permission directly from the copyright holder. To view a copy of this licence, visit http://creativecommons.org/licenses/by/4.0/ The Creative Commons Public Domain Dedication waiver (http://creativecommons.org/publicdomain/zero/1.0/) applies to the data made available in this article, unless otherwise stated in a credit line to the data. 


\section{Background}

Small cell lung cancer (SCLC) is the most aggressive and deadly form of lung cancer characterised by rapid growth, early metastasis, and high rates of acquired therapeutic resistance $[1,2]$. Due to the nature of the disease, the majority of patients have metastatic disease at time of diagnosis leading to poor overall survival (OS) [3]. Over the last decades, improvements in cancer treatment have led to improved survival in non-small cell lung cancer (NSCLC) [4], but in SCLC patients, this impact on OS has been absent until lately, where the introduction of immunotherapy has shown promising results in clinical trials for this patient group $[5,6]$. Though not all patients benefit from the available treatments, and for some patients, the course of the disease at time of diagnosis is fast and aggressive, therefore, the clinicians need guiding tools to predict the patient's prognosis and the natural history of the disease. Moreover, to make improvements in the treatment of SCLC patients, we need prognostic markers that can identify patients who are at high risk of an inferior survival. By doing so, patients can be stratified into optimal treatment regimens or follow-up programmes which hopefully will lead to improved patient survival.

As one of the hallmarks of cancer [7], inflammation has been suggested as a prognostic marker [8]. Hence, general inflammation markers like $\mathrm{C}$-reactive protein (CRP), leucocytes, or lymphocytes have been studied and shown some potential as prognostic markers in several cancers, even though results have been conflicting [9, 10]. Using individual inflammation markers as a measure of the inflammation status is a simplistic approach to a complex system. Therefore, inflammation scores that combine these general inflammation markers have been developed and proven to be prognostic markers of inferior survival in several cancers including NSCLC [10-15]. In SCLC, however, the prognostic value of inflammation scores is less studied, just as studies have shown inconsistent results $[16,17]$. Therefore, we performed a systematic review to explore the literature on inflammation scores in SCLC. Furthermore, we performed a metaanalysis to investigate the prognostic value of pretreatment neutrophil-to-lymphocyte ratio (NLR) and platelet-to-lymphocyte ratio (PLR) in SCLC patients.

\section{Materials and methods}

\section{Data sources and search strings}

A systematic search was carried out investigating the existing literature of inflammation scores in SCLC. The review was performed following the Preferred Reporting Items for Systematic Reviews and Meta-Analyses (PRIS MA) guidelines [18]. The search was made in the databases PubMed, MEDLINE, Embase, and Web of Science on the 20th of March, 2020 with no time restriction. All databases were filtered for English, and PubMed and Embase were filtered for "not animals" in addition. Studies were selected using terms defining Lung cancer ("Lung cancer", "Lung neoplasm"”, "Lung Neoplasms"[Mesh], "Lung carcinoma"), general inflammation markers ("Lymphocyte" " "Lymphocytes"[Mesh], "Lymphocyte Count"[Mesh], "Neutrophil", "albumin", "Neutrophils"[Mesh], "CRP", "Creactive protein", "C-Reactive Protein"[Mesh], "albumin", "Albumins"[Mesh]) and inflammation based scores ("glasgow prognostic score"", "neutrophil to lymphocyte ratio", "neutrophil-lymphocyte ratio", "lymphocyte ratio", "inflammation score", "inflammation-based score", "inflammation index"). The full search string is available in Supplementary Text S1.

\section{Inclusion and exclusion criteria}

The studies included in this review met the following inclusion criteria: (1) original data, (2) human studies, (3) patients with a pathologically proven histology of SCLC, and (4) studies evaluating a combination of general inflammation markers as a prognostic factor. Studies were excluded based on the following exclusion criteria: (1) language other than English; (2) papers without original data as reviews, meta-analyses, guidelines, editorials, comments, and letters to the editor; (3) conference abstracts or case reports including fewer than five cases; and (4) animal or in vitro studies. In case of two publications based entirely or partly on the same study population, the study containing the highest number of patients was included. According to the inclusion and exclusion criteria, two authors (BSP and AWL) screened the first 500 titles and abstracts to validate the inclusion and exclusion criteria. Disagreements were settled by discussion and consensus. The remaining titles and abstracts were screened by BSP. Two authors (BSP and AWL) read and included/excluded 30 randomly selected articles, and the remaining articles were assessed by BSP. The reference management tools Endnote (Clarivate Analytics) and Covidence (covidence.org) were used for identification of duplicates.

\section{Data extraction and quality assessment}

Data extracted from the studies included name of first author, publication year, inclusion period, sample size, study design, and follow-up time. Furthermore, clinical characteristics of the study population and information on the inflammation score including cut-off, and risk estimates of the association with OS were extracted. Studies were split into two, and data extraction was performed by two authors (BSP and AWL); each author extracting data from half of the studies. All data extraction were checked by the other author. Both authors quality assessed the articles included in the study based on a modified version of the Quality of Prognosis 
Studies Tool (QUIPS) [19], and articles were rated as high quality, moderate, or low quality. The protocol for the study was submitted to the PROSPERO database (registration number CRD42020188553).

\section{Statistical analyses}

For the individual inflammation score, a meta-analysis was performed if the score was evaluated in at least five studies with extractable risk estimates. Risk estimates included in the study were HR for the inflammation scores association with OS along with a $95 \% \mathrm{CI}$ values or a beta coefficient and a standard error. Publication bias was evaluated by visual inspection of a funnel plot and by the Begg's and Egger's tests. Heterogeneity between the included studies was tested by using the Cochran $Q$ and $I^{2}$ [20], where $I^{2}<50 \%$ and $p>0.10$ were set as cut-offs to define heterogeneity. In case of no significant heterogeneity, a fixed-effects model was applied; otherwise, a random-effects model was used. Sensitivity analyses were performed by excluding the low-quality studies and studies with predefined cut-offs to assess the robustness of the pooled estimate. Data were analysed by Stata software version 15.1 (Stata Corporation, College Station, TX, USA), and all $p$ values were two-sided and considered significant if $<0.05$.

\section{Results}

\section{Study selection}

A total of 5563 publications were identified through searching the online databases; 2570 of these were excluded due to duplication. Titles and abstracts were screened for eligibility which led to exclusion of 2891 irrelevant articles. Full texts of the remaining 102 articles were thoroughly reviewed, and 70 articles were excluded due to various reasons: abstract, $n=26$; not possible to extract data on SCLC, $n=23$; no data on outcome, $n=$ 8; no data on SCLC patients, $n=5$; no original data, $n=$ 3 ; other language than English, $n=2$; overlapping cohort, $n=2$; wrong subject, $n=1$. Finally, 33 articles met the inclusion criteria for the current systematic review. The inclusion and exclusion procedures are illustrated in Fig. 1.

\section{Study description and quality assessment}

Baseline characteristics of the studies included are listed in Table 1. In summary, all included studies were retrospective studies published between 2008 and 2020. The majority of studies were conducted in Asia $(n=23)$ [17, $21,23-25,27-30,32,33,36-38,41-44,46-49]$, primarily China, whereas eight studies $[16,22,26,31,34,35$, 50, 51] originated from Europe and two from the USA $[39,40,45]$. A total of 7762 patients with SCLC were included with the number of patients included in each study ranging from 46 to 938 . In more than half of the studies $(n=19)[17,21,23-25,27-30,33,36,37,41,42$, $44,45,48-50]$, the included patients were a mixture of patients with limited disease (LD) and patients with extended disease (ED), whereas only patients with LD were included in eight studies [16, 26, 31, 34, 40, 43, 46, 47] and only patients with ED were included in five studies $[32,35,38,39,51]$. For one study, the stage of disease was not described [22]. The presence of liver metastasis was described in seven studies [30, 32, 35, 38, 45, 48, 51] and ranged from 16 to $47 \%$ of patients with ED. The

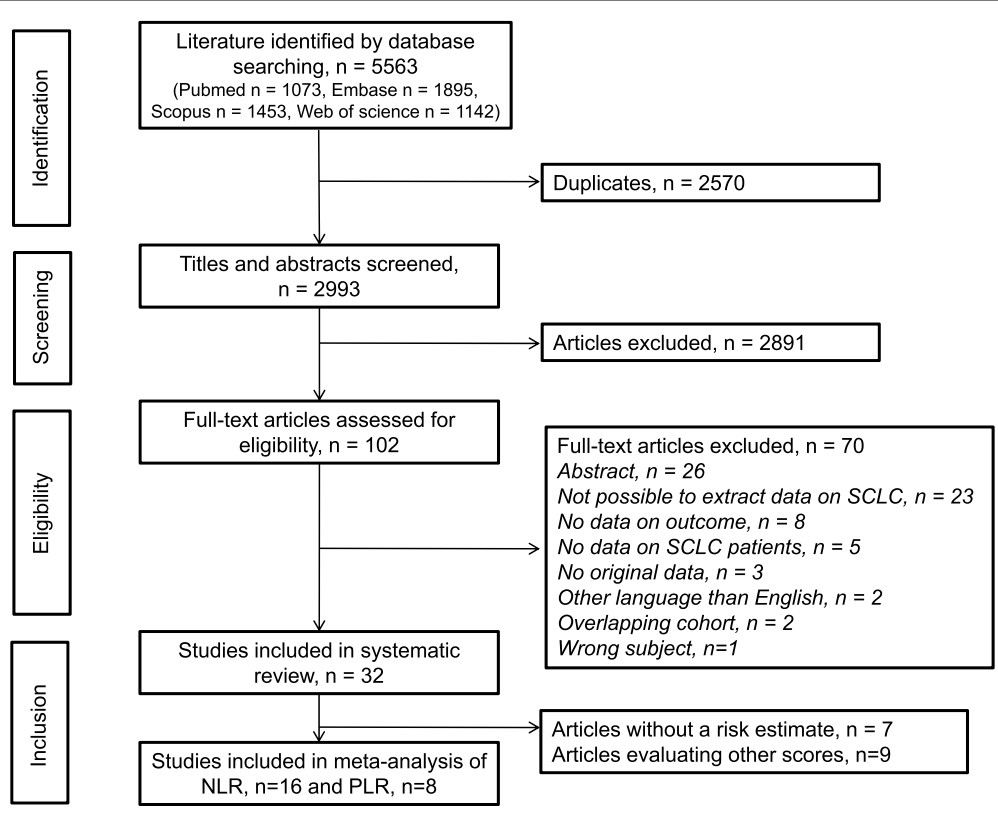

Fig. 1 Flow chart of the inclusion and exclusion procedures. SCLC, small cell lung cancer 


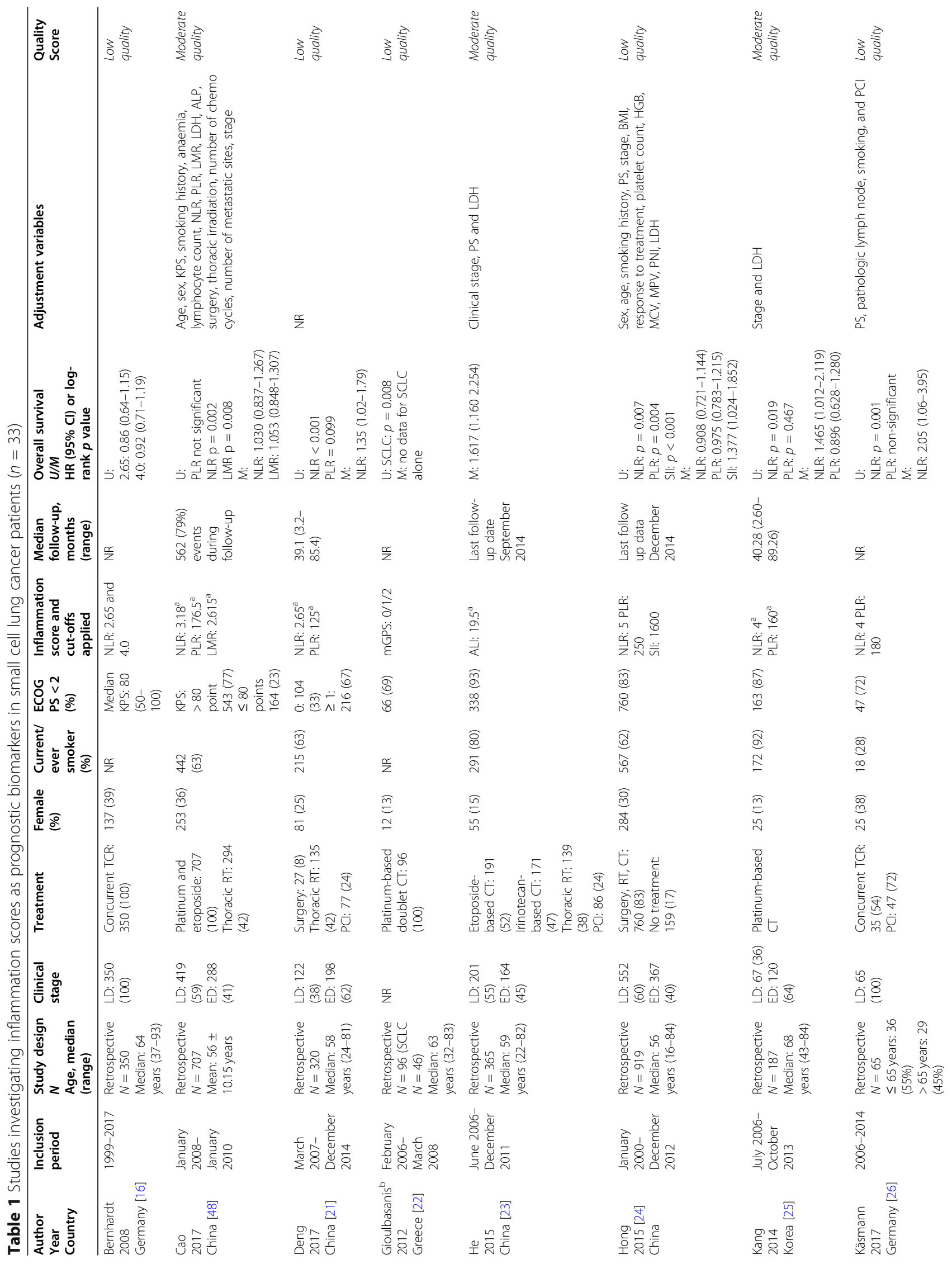




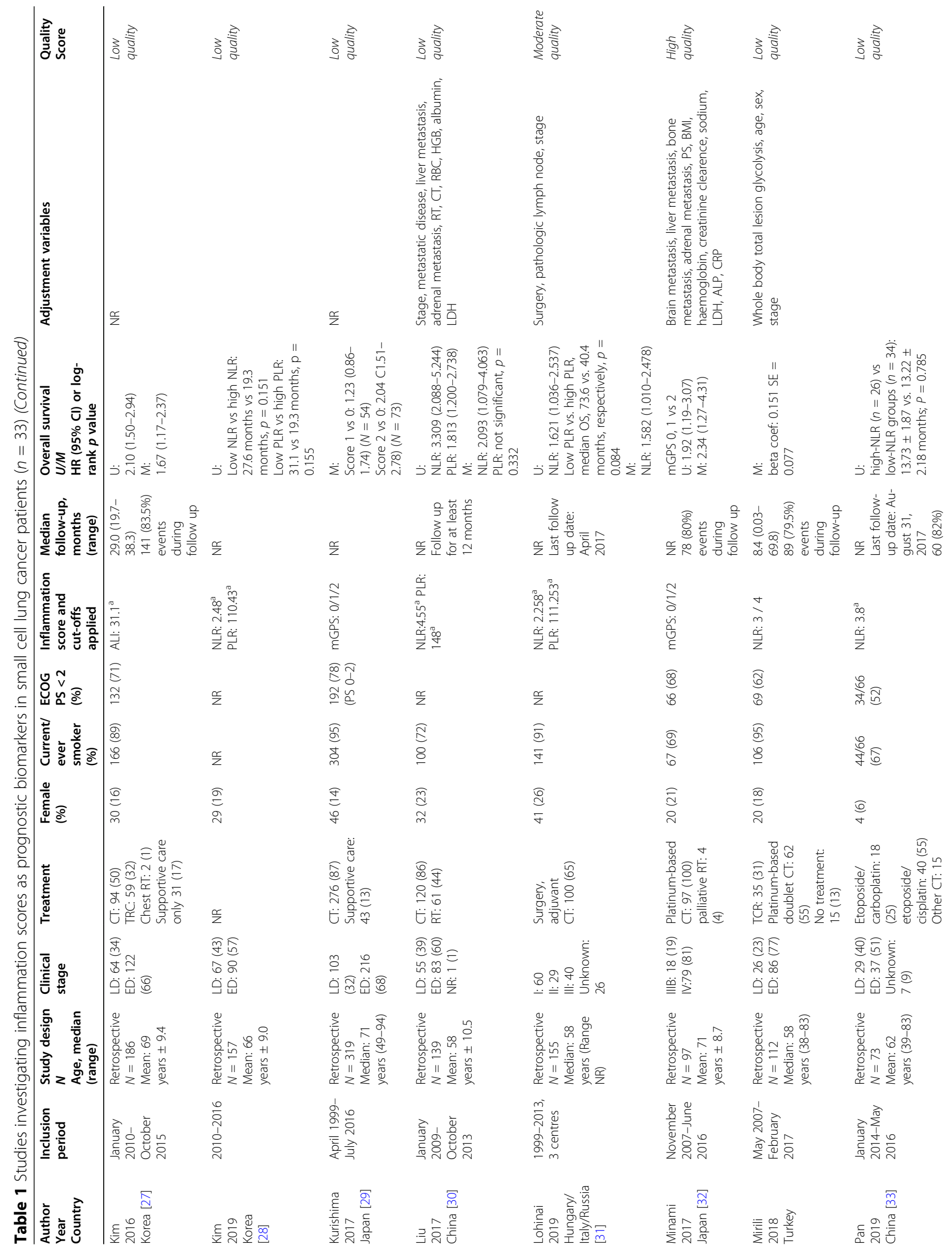




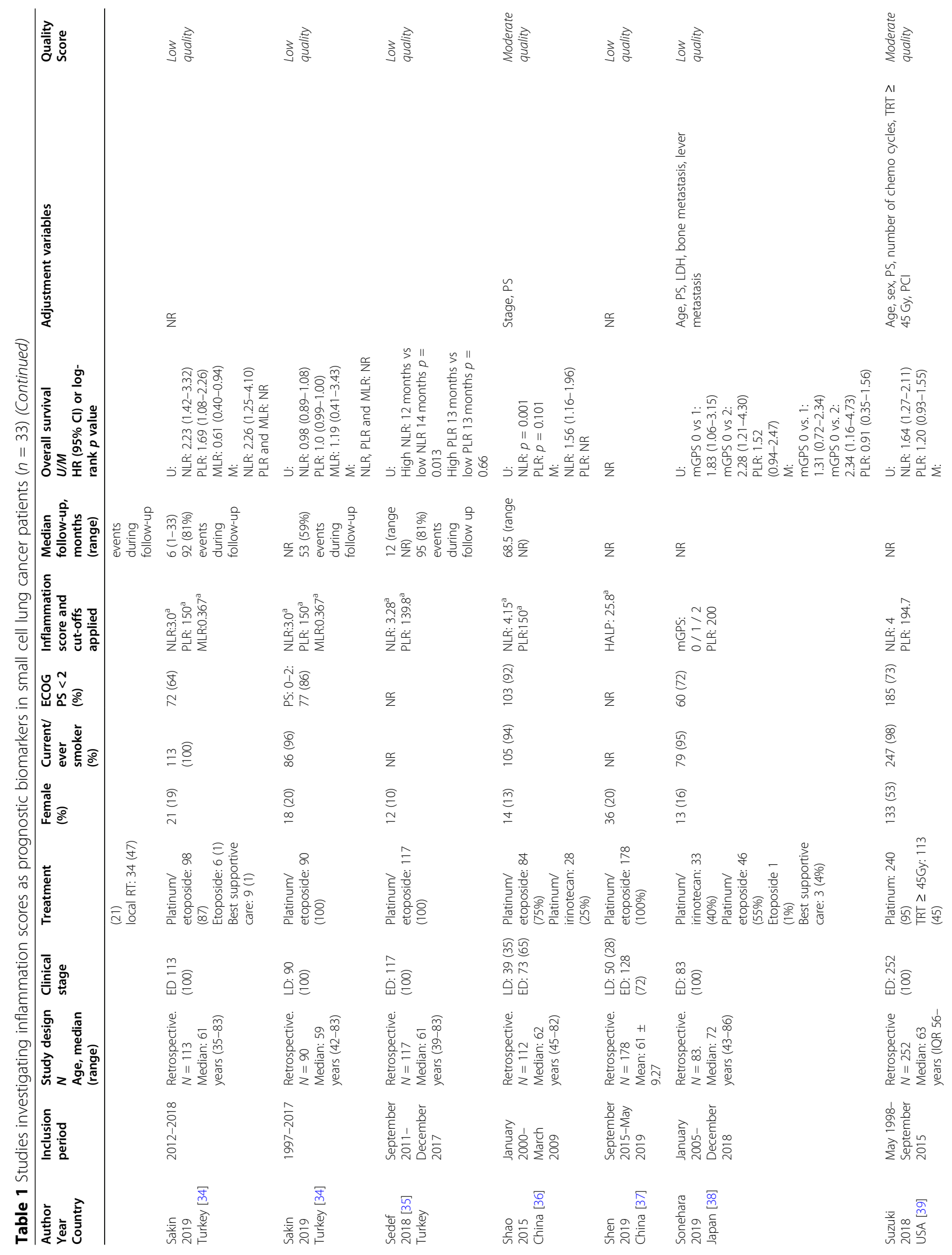




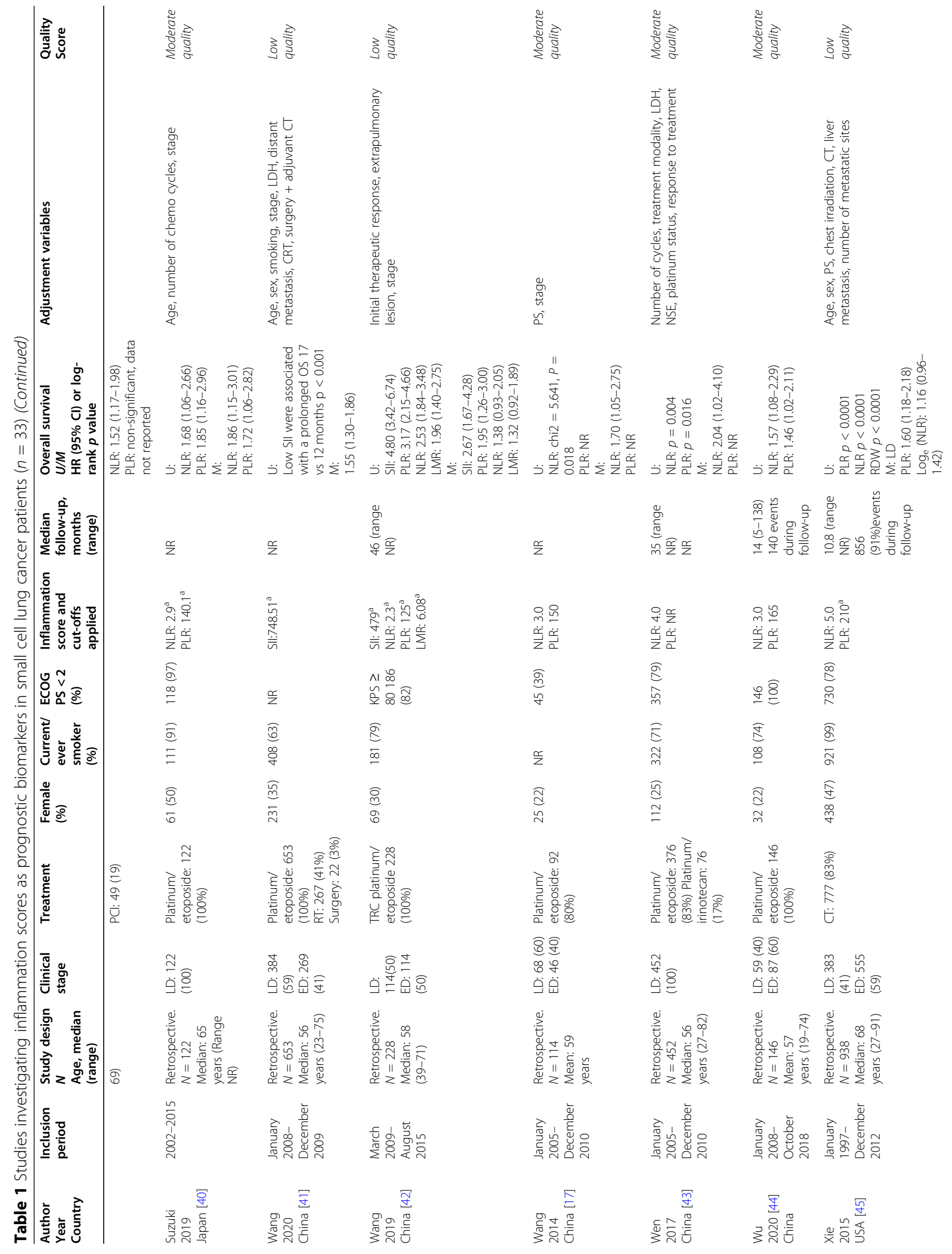




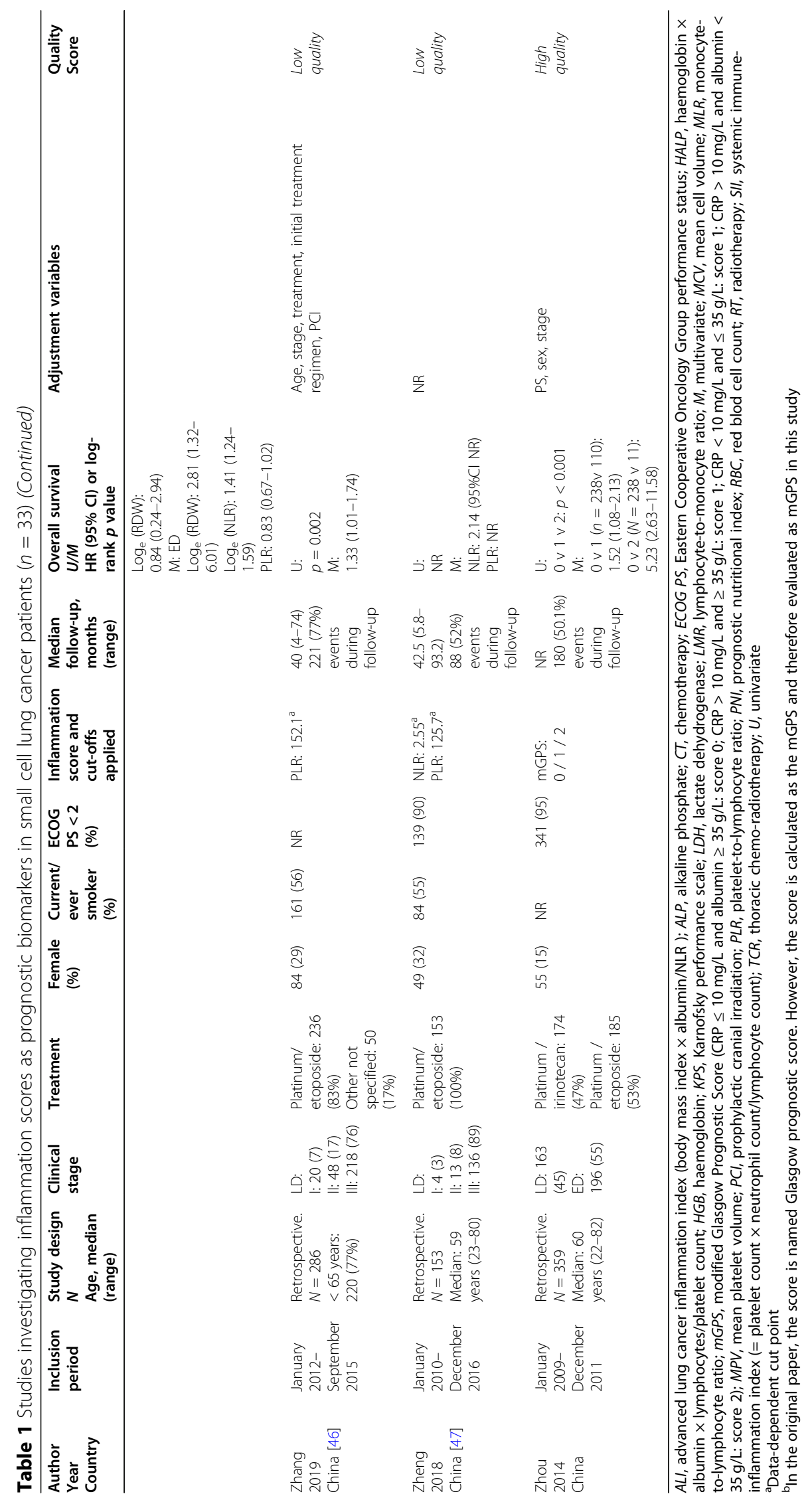


median/mean age of included patients varied from 56 to 72 years, and $6-50 \%$ of the included patients were female. Smoking was assessed in 26 studies [21, 23-27, $29-34,36,38-48,50,51]$ demonstrating that $28-100 \%$ of the patients had a history of smoking. Furthermore, the performance status was estimated in 26 studies [16, $17,21-27,29,32-34,36,38-40,42-45,47-51]$ demonstrating that $33-100 \%$ of the patients were in a good performance defined by Eastern Cooperative Oncology Group Performance Status $<2$ or Karnofsky performance scale $\geq 80$.

Eight different inflammation-based scores were identified. The inflammation-based scores neutrocyte-tolymphocyte ratio (NLR) and platelet-to-lymphocyte ratio (PLR) were the most frequently evaluated (NLR: $n=23$; PLR: $n=22$ ). Other identified inflammation-based scores were modified Glasgow prognostic score (mGPS, $n=5$ ), lymphocyte-to-monocyte ratio (LMR, $n=2$ ), monocyteto-lymphocyte ratio (MLR, $n=2$ ), advanced lung cancer inflammation index (ALI, $n=2$ ), systemic immuneinflammation index (SII, $n=2$ ), and haemoglobin, albumin, lymphocyte, and platelet score (HALP, $n=1$ ).

For mGPS, cut-offs were identical and predefined in all studies. For the remaining scores, predefined cut-offs were defined in seven studies [16, 17, 24, 26, 43, 44, 50], while data-dependent cut-offs were employed in 19 studies $[21,23,25,27,28,30,31,33-37,40-42,46-48$, 51]. In two studies evaluating different scores, NLR was evaluated based on a predefined cut-off, whereas the cut-off for PLR were data dependent $[39,45]$. As a consequence, cut-offs varied substantially for NLR, 2.3-5.0; PLR, 110.43-250; LMR, 2.615-6.08; ALI, 19.5-31.1; and SII, 748.51-1600. The inflammation scores were evaluated as prognostic biomarkers based on a blood sample collected at diagnosis of the lung cancer $(n=8)[21,24-$ $27,29,33,50]$ or before start of treatment $(n=23)[16$, $17,22,23,28,30-32,34-37,39-47,49,51]$. For two studies $[38,48]$, the time of blood sampling was not reported. Based on the quality assessment, included studies were ranked from low to high quality; 21 studies were ranked low quality $[16,21,22,24,26-30,33-35$, $37,38,41,42,45-47,50,51]$, ten studies ranked moderate quality $[17,23,25,31,36,39,40,43,44,48]$, and two studies ranked high quality [32, 49].

\section{Inflammation scores and overall survival}

In the identified 33 studies, an adjusted risk estimate of mortality risk between patients with a low versus a high score could only be retrieved in 25 studies (NLR, 16 [17, 21, 24-26, 30, 31, 36, 39, 40, 42, 43, 45, 48, 50, 51]; PLR, 7 [24, 25, 38, 40, 42, 45, 46]; LMR, 2 [42, 48]; MLR, 2 [34, 51]; mGPS, 4 [29, 32, 38, 49]; SII, 3 [24, 41, 42]; ALI, $1[23,27])$. Rating and adjustment variables for the individual study are listed in Table 1 . The studies were rated from low quality to high quality. The applied adjustment variables were reported in 20 studies [17, 23$26,30-32,36,38-43,45,46,48-50]$ while no information on adjustment variables were reported in five studies [21, 27, 29, 47, 51]. For inflammation-based scores evaluated in more than five studies, a meta-analysis was performed.

\section{$N L R$ and overall survival}

A substantial between-study heterogeneity was observed in the 16 studies evaluating NLR $(Q=43.62$ on $16 \mathrm{df} ; P$ $<0.0001 ; I^{2}=63.3 \% ; p=0.03$ ), why a pooled HR was estimated using a random-effects model. A high NLR was found to be associated with a $39 \%$ increased risk of death in patients with SCLC (HR $=1.39$ (95\% CI, 1.231.56), Fig. 2).

Due to an observed asymmetry in the funnel plot, publication bias was suspected (Supplementary Figure 1), which was supported by the Eggers test $(p=0.04)$ and a tendency observed in the Begg's test $(p=0.06)$. Hence, a Trim and Fill analysis was performed to account for absent studies, and an adjusted pooled random-effects HR was calculated. The pooled HR remained significant, even though the estimate was slightly reduced $(\mathrm{HR}=$ 1.23 (95\% CI, 1.13-1.42)).

Since the meta-analysis included a large number of studies ranked low quality, a sensitivity analysis was performed including only the moderate quality ranked studies. Evaluating only the nine studies of moderate quality, we found a pooled HR of 1.51 (95\% CI, 1.29-1.81). Furthermore, in nine studies, data-dependent cut-points were applied; hence, a sensitivity analysis was performed including only studies with predefined cut-points. Here we found a pooled HR of 1.34 (95\% CI, 1.15-1.58).

\section{PLR and overall survival}

In the studies of PLR, a considerable between-study heterogeneity was also detected $(Q=26.87$ on $7 \mathrm{df} ; P$ $<0.0001 ; I^{2}=74 \% ; p=0.12$ ), and again, a pooled HR was estimated using a random-effects model. A high PLR was associated with a $20 \%$ increased risk of death in patients with SCLC; however, the estimate of the risk increase was ranged from -4 to $51 \%(\mathrm{HR}=$ 1.20 (95\% CI, 0.96-1.51), Fig. 3). An asymmetry in the funnel plot was observed and publication bias was suspected (Supplementary Figure 2). However, Begg's test $(p=0.17)$ and Egger's test $(p=0.22)$ did not identify publication bias.

\section{Discussion}

In this systematic review, we explored the literature on inflammation scores as prognostic biomarkers in SCLC. We identified eight different inflammation scores and evaluated their ability to predict OS in SCLC. By the use 


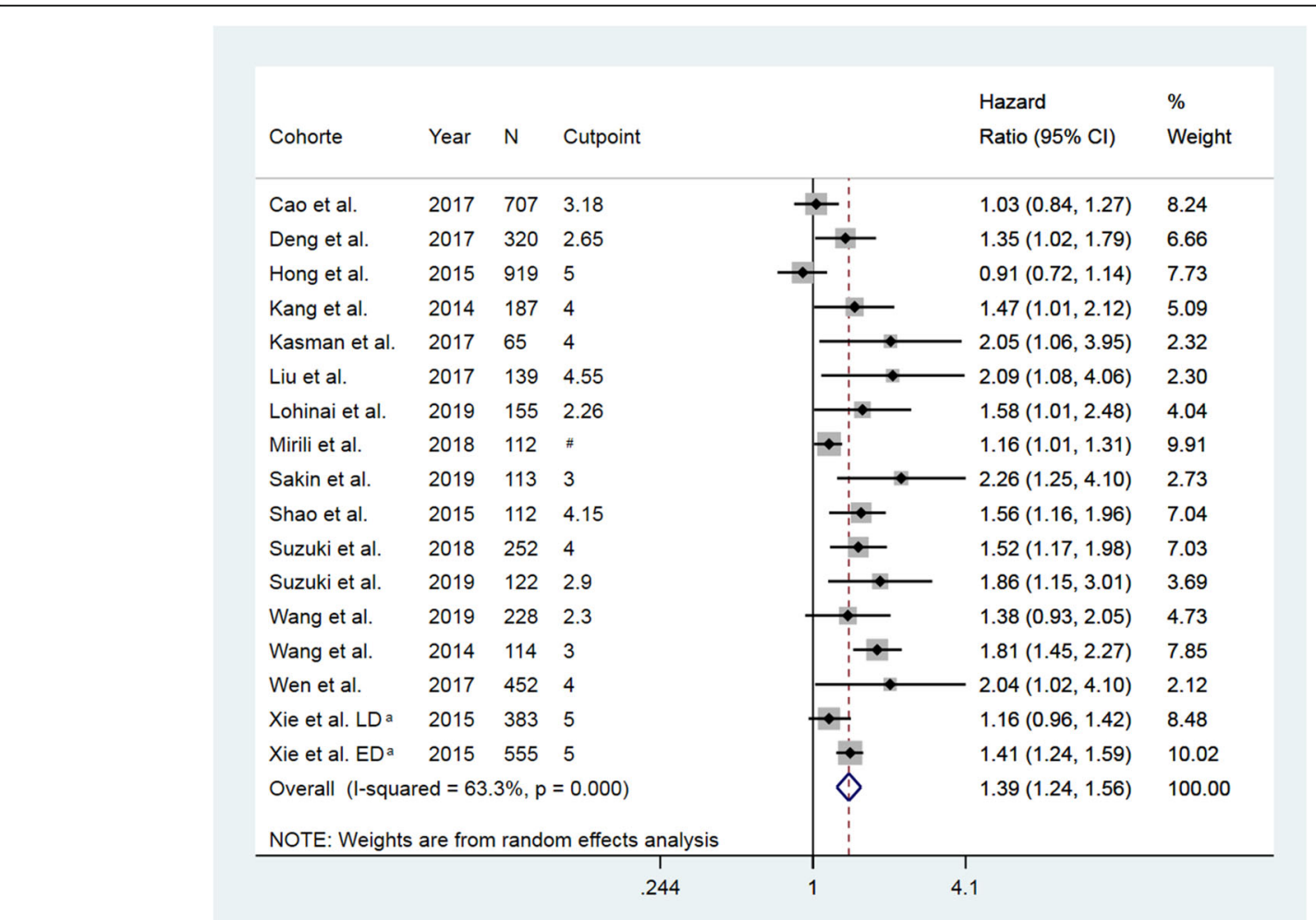

Fig. 2 Forrest plot of hazard ratio for the association between neutrophil-to-lymphocyte ratio and overall survival in patients with small cell lung cancer. N, number of included patients; Cl, confidence interval; LD, limited disease; ED, extended disease. " Two cut-points (NLR 3 and 4) were evaluated. ${ }^{a} N L R$ were evaluated in two individual subgroups: LD and ED

of meta-analyses, we demonstrated that NLR leads to a $39 \%$ increase in mortality in SCLC patients. This finding was confirmed after taking the risk of publication bias into account, even though the pooled HR was reduced. Opposite, no association with OS could not be confirmed for PLR. All studies included in the review were retrospective studies, just as the overall quality of the studies was low. Nevertheless, the association was confirmed after omitting low-quality studies from the analysis. Regardless of these hesitations, as the first, this review collects the available literature on inflammation scores in SCLC and evaluates their potential as prognostic biomarkers in SCLC.

Inflammation is recognised as one of the hallmarks of cancer, why inflammation scores based on general inflammation markers have been demonstrated as a prognostic biomarker in several cancers [10-15]. Though, so far a hypothesis explaining the biological mechanisms behind these various inflammation scores, and especially, a hypothesis explaining why inflammation scores are associated with mortality, has been absent. A potential part of this puzzle could be interleukin-1 $\beta$, as inhibition of interleukin-1 $\beta$ was shown to lead to a decrease in lung cancer incidence as well as mortality in atherosclerotic patients [52], and high levels of interleukin- $1 \beta$ has been observed along with anaemia, neutrophilia, lymphopenia, low levels of albumin, and increased CRP in patients with rheumatic disease [53]. In this comprehensive review, all identified inflammation scores, but mGPS, were based on lymphocyte count in various combinations with neutrophils, platelets, monocytes, albumin, haemoglobin, and BMI. NLR was the most frequently evaluated score $(n=23)$ closely followed by PLR $(n=22)$. For NLR, which can be a reflection of interleukin- $1 \beta$ associated neutrophilia and lymphopenia, high scores were related to inferior survival. Similarly, in the NLR-modified scores (ALI and SII) a high score was associated with inferior survival. For PLR, however, the association with OS could not be confirmed. A possible explanation for this could be that the PLR only includes one general inflammation marker (lymphocyte) affected by the interleukin-1 $\beta$. Consequently, the HALP score, which is a modification of the PLR by including haemoglobin and albumin, should have an improved association with survival theoretically. Unfortunately, however, survival data were not reported for the HALP score [37]. The only score not including lymphocyte count is the mGPS, which is based on two other markers potentially reflecting interleukin-1 $\beta$ : albumin and CRP. We identified five studies [22, 29, 32, 38, 49] evaluating the prognostic 


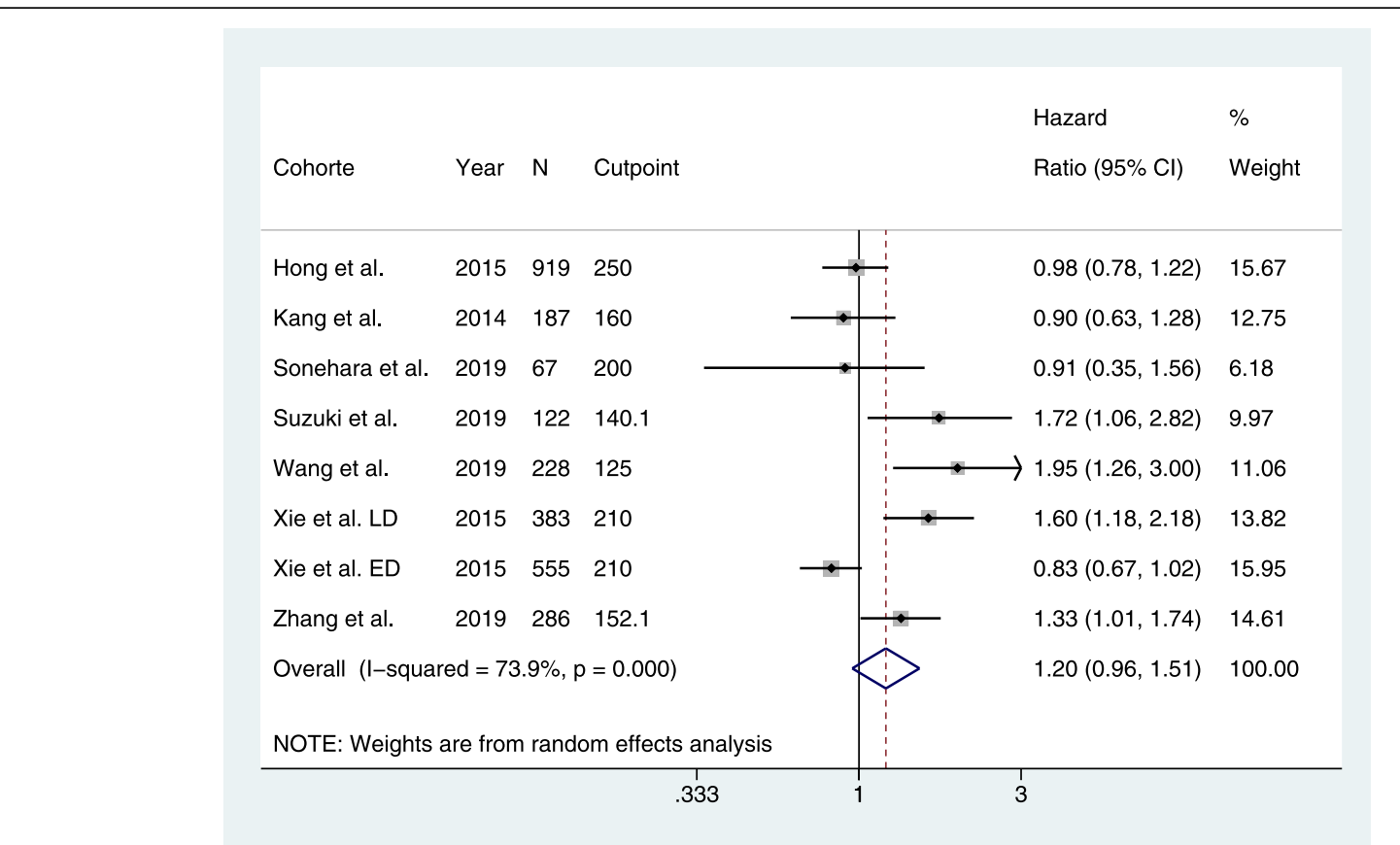

Fig. 3 Forrest plot of hazard ratio for the association between platelet-to-lymphocyte ratio and overall survival in patients with small cell lung cancer. N, number of included patients; $\mathrm{Cl}$, confidence interval; LD, limited disease; ED, extended disease. ${ }^{a} \mathrm{PLR}$ were evaluated in two individual subgroups: $L D$ and $E D$

potential of mGPS in a total of 954 SCLC patients with both LD and ED. A high mGPS score was overall associated with reduced OS, though one of the studies [22] did not report an adjusted HR. Due to the low number of studies, a meta-analysis could not be performed. However, in other cancer types like NSCLC, the prognostic value of mGPS has been established even in meta-analyses [54, 55] indicating that mGPS could be a valuable biomarker in SCLC as well.

In all scores except mGPS, data-dependent cut-offs based on survival were frequently applied $(n=19)$. When survival is used to decide how to define a cut-off in a given biomarker, the likelihood of the given biomarkers' ability to be able to predict survival is enlarged enormously. Thus, this could be a potential bias to this study. Therefore, we performed a subgroup analysis excluding studies with data-dependent cut-offs and demonstrated only a slight reduction of the combined risk estimate indicating that data-dependent cut-offs were not a major bias in our study. Furthermore, due to the data-dependent nature of cut-offs, the cut-offs varied tremendously for all scores with a tendency of higher predefined cut-offs compared to data-dependent cutoffs.

Until now, only one systematic review on NLR in SCLC has been performed [56] identifying an association between NLR and OS. In the previous review, 21 studies were included of which six were posters from international conferences and two of these could not be identified in the PubMed, Embase, WOS, or Scopus databases. Moreover, a quality assessment was not performed in the previous review. Besides, in this study, 13 additional studies evaluating NLR as a prognostic marker in SCLC were identified owed to the comprehensive search, leading to a more wide-ranging evaluation of NLR as a prognostic biomarker.

The strength of this study is the comprehensive systematic review of the available literature on inflammation scores in SCLC. We used four internationally recognised databases applying broad search terms to include all inflammation scores available. Though we included specific search terms for well-known scores as NLR, PLR, and mGPS, thus, the likelihood of retrieving more results on these specific scores is present. To counter this potential skewness in identified scores, we included broad search terms in our search strategy including individual inflammation markers and various terms covering the inflammation score term. An additional strength of the review is the quality assessment performed by two authors. The quality assessment is essential to identify biases of a magnitude to affect study results. We applied a modified version of the QUIPS [19], which assesses six important domains being: study participation, study attrition, prognostic factor measurement, confounding, measurement and account, outcome measurement, and analysis and reporting.

Nevertheless, the study faces some limitations. Firstly, all studies were retrospective and the overall quality of 
the included studies was low. Additionally, substantial heterogeneity was observed between the included studies as $I^{2}$ values of $63 \%$ for NLR and 74\% for SCLC were observed. The $I^{2}$ measure the variation in the estimates caused by-study differences. In general, an $I^{2}>=50 \%$ indicate moderate heterogeneity and an $I^{2}>75 \%$ indicate substantial to considerable heterogeneity [57]. These thresholds are arbitrary. However, the $I^{2}$ cannot stand alone but should be considered in combination with the forest plot. If the estimates vary but point towards the same conclusion in the forest plot as is seen for NLR (Fig. 1) and PLR (Fig. 2), a substantial heterogeneity can be present, but it would be of questionable clinical importance [57]. Finally, a language bias cannot be excluded as we only included studies written in English.

\section{Conclusion}

This review identifies that inflammation scores based on general inflammation markers do have some potential as prognostic markers in SCLC patients. The conducted meta-analyses demonstrated that NLR was associated with mortality. Furthermore, mGPS showed some potential as a prognostic marker of inferior survival, though only in a limited number of studies. Hence, inflammation scores as NLR could be clinically relevant as a prognostic marker in the treatment of SCLC patients.

\section{Supplementary Information}

The online version contains supplementary material available at https://doi. org/10.1186/s13643-021-01585-w.

\section{Additional file 1: Supplementary Figure 1. Funnel plot for the} analysis of publication bias in studies evaluating neutrophil-tolymphocyte ratio (NLR) as prognostic markers of overall survival in patients with small cell lung cancer. HR, hazard ratio.

Additional file 2: Supplementary Figure 2. Funnel plot for the analysis of publication bias in studies evaluating platelet-to-lymphocyte ratio (PLR) as prognostic markers of overall survival in patients with small cell lung cancer. $\mathrm{HR}$, hazard ratio.

\section{Abbreviations}

ALI: Advanced lung cancer inflammation index; Cl: Confidence interval; CRP: c-reactive protein; ED: Extended disease; HALP: Haemoglobin, albumin, lymphocyte, and platelet score; HR: Hazard ratio; LD: Limited disease; LMR: Lymphocyte-to-monocyte ratio; mGPS: Modified Glasgow prognostic score; MLR: Monocyte-to-lymphocyte ratio; NLR: Neutrophil-to-lymphocyte ratio; NSCLC: Non-small lung cancer; OS: Overall survival; PLR: Platelet-tolymphocyte ratio; PRISMA: Preferred Reporting Items for Systematic Reviews and Meta-Analyses; QUIPS: Quality of Prognosis Studies Tool; SII: Systemic immune-inflammation indexSCLCSmall cell lung cancer

\section{Acknowledgements}

Not applicable

\section{Authors' contributions}

(I) Conception and design: Anne Winther-Larsen and Birgitte Sandfeld-Paulsen. (II) Administrative support: Anne Winther-Larsen and Birgitte Sandfeld-Paulsen. (III) Provision of study materials or patients: Anne Winther-Larsen and Birgitte Sandfeld-Paulsen. (IV) Collection and assembly of data: Anne Winther-Larsen and Birgitte Sandfeld-Paulsen. (V) Data analysis and interpretation: Ninna
Aggerholm-Pedersen, Anne Winther-Larsen and Birgitte Sandfeld-Paulsen. (VI) Manuscript writing: All authors. (VII) Final approval of manuscript: All authors.

Funding

The authors did not receive specific funding for this study.

\section{Availability of data and materials}

The datasets used and/or analysed during the current study are available from the corresponding author on reasonable request.

Ethics approval and consent to participate

In agreement with the Danish legislation and the Danish National Committee in Health Research Ethics, this study did not require formal approval.

\section{Consent for publication}

The study did not contain any data of individual persons just as case reports including fewer than five cases were excluded.

\section{Competing interests}

The authors have no conflicts of interest to declare.

\section{Author details}

${ }^{1}$ Department of Clinical Biochemistry, Viborg Regional Hospital, Viborg, Denmark. Department of Clinical Oncology, Aarhus University Hospital, Aarhus, Denmark. ${ }^{3}$ Department of Clinical Biochemistry, Aarhus University Hospital, Palle Juul-Jensens Boulevard 99, 8200 Aarhus N, Denmark.

Received: 12 October 2020 Accepted: 6 January 2021

Published online: 28 January 2021

\section{References}

1. Gazdar AF, Bunn PA, Minna JD. Small-cell lung cancer: what we know, what we need to know and the path forward. Nat Rev Cancer. 2017;17(12):72537.

2. Sabari JK, Lok BH, Laird JH, Poirier JT, Rudin CM. Unravelling the biology of SCLC: implications for therapy. Nat Rev Clin Oncol. 2017;14(9):549-61.

3. Torre LA, Bray F, Siegel RL, Ferlay J, Lortet-Tieulent J, Jemal A. Global cancer statistics, 2012. CA Cancer J Clin. 2015;65(2):87-108.

4. Hirsch FR, Scagliotti GV, Mulshine JL, Kwon R, Curran WJ Jr, Wu YL, et al. Lung cancer: current therapies and new targeted treatments. Lancet. 2017; 389(10066):299-311.

5. Chung HC, Lopez-Martin JA, Kao SCH, Miller WH, Ros W, Gao B, et al. Phase 2 study of pembrolizumab in advanced small-cell lung cancer (SCLC): KEYNOTE-158. J Clin Oncol. 2018;36(15):8506.

6. Ready N, Farago AF, de Braud F, Atmaca A, Hellmann MD, Schneider JG, et al. Third-line Nivolumab Monotherapy in recurrent SCLC: CheckMate 032 J Thorac Oncol. 2019;14(2):237-44.

7. Hanahan D, Weinberg RA. Hallmarks of cancer: the next generation. Cell. 2011;144(5):646-74.

8. McMillan DC. The systemic inflammation-based Glasgow prognostic score: a decade of experience in patients with cancer. Cancer Treat Rev. 2013;39(5): 534-40.

9. Allin $\mathrm{KH}$, Nordestgaard BG. Elevated C-reactive protein in the diagnosis, prognosis, and cause of cancer. Crit Rev Clin Lab Sci. 2011;48(4):155-70. https://doi.org/10.3109/10408363.2011.599831

10. Wang DS, Luo HY, Qiu MZ, Wang ZQ, Zhang DS, Wang FH, et al. Comparison of the prognostic values of various inflammation based factors in patients with pancreatic cancer. Med Oncol. 2012;29(5):3092-100.

11. Lorente D, Mateo J, Templeton AJ, Zafeiriou Z, Bianchini D, Ferraldeschi R, et al. Baseline neutrophil-lymphocyte ratio (NLR) is associated with survival and response to treatment with second-line chemotherapy for advanced prostate cancer independent of baseline steroid use. Ann Oncol. 2015;26(4): 750-5.

12. Koh CH, Bhoo-Pathy N, Ng KL, Jabir RS, Tan GH, See MH, et al. Utility of pretreatment neutrophil-lymphocyte ratio and platelet-lymphocyte ratio as prognostic factors in breast cancer. Br J Cancer. 2015;113(1):150-8.

13. Proctor MJ, McMillan DC, Morrison DS, Fletcher CD, Horgan PG, Clarke SJ. A derived neutrophil to lymphocyte ratio predicts survival in patients with cancer. Br J Cancer. 2012;107(4):695-9. 
14. Shiba H, Misawa T, Fujiwara Y, Futagawa Y, Furukawa K, Haruki K, et al. Glasgow prognostic score predicts outcome after surgical resection of gallbladder cancer. World J Surg. 2015;39(3):753-8.

15. Hwang JJ, Choi CW, Yoo JH, Kim DH, Kang HM, Park MJ. Preoperative cell counts of white blood cell, neutrophil, lymphocyte and neutrophil/ lymphocyte ratio as a predictive parameter of survival rate after complete resection for non-small cell lung cancer. Eur Respir J. 2016;48:2844.

16. Bernhardt D, Aufderstrasse S, Konig L, Adeberg S, Bozorgmehr F, Christopoulos $P$, et al. Impact of inflammatory markers on survival in patients with limited disease small-cell lung cancer undergoing chemoradiotherapy. Cancer Manag Res. 2018;10:6563-9.

17. Wang $X$, Jiang R, Li K. Prognostic significance of pretreatment laboratory parameters in combined small-cell lung cancer. Cell Biochem Biophys. 2014; 69(3):633-40. https://doi.org/10.1007/s12013-014-9845-3.

18. Liberati A, Altman DG, Tetzlaff J, Mulrow C, Gøtzsche PC, loannidis JP, et al. The PRISMA statement for reporting systematic reviews and meta-analyses of studies that evaluate health care interventions: explanation and elaboration. J Clin Epidemiol. 2009;62(10):e1-34.

19. Hayden JA, van der Windt DA, Cartwright JL, Côté P, Bombardier C. Assessing bias in studies of prognostic factors. Ann Intern Med. 2013;158(4):280-6.

20. Higgins JP, Thompson SG, Deeks JJ, Altman DG. Measuring inconsistency in meta-analyses. Bmj. 2003;327(7414):557-60.

21. Deng $M$, Ma X, Liang X, Zhu C, Wang M. Are pretreatment neutrophillymphocyte ratio and platelet-lymphocyte ratio useful in predicting the outcomes of patients with small-cell lung cancer? Oncotarget. 2017;8(23): 37200-7. https://doi.org/10.18632/oncotarget.6553.

22. Gioulbasanis I, Pallis A, Vlachostergios PJ, Xyrafas A, Giannousi Z, Perdikouri IE, et al. The Glasgow prognostic score (GPS) predicts toxicity and efficacy in platinum-based treated patients with metastatic lung cancer. Lung Cancer. 2012;77(2):383-8. https://doi.org/10.1016/j.lungcan.2012.04.008 Epub Apr 30.

23. He X, Zhou T, Yang Y, Hong S, Zhan J, Hu Z, et al. Advanced lung cancer inflammation index, a new prognostic score, predicts outcome in patients with small-cell lung cancer. Clin Lung Cancer. 2015;16(6):e165-71. https:// doi.org/10.1016/j.cllc.2015.03.005 Epub Mar 26.

24. Hong X, Cui B, Wang M, Yang Z, Wang L, Xu Q. Systemic immuneinflammation index, based on platelet counts and neutrophil-lymphocyte ratio, is useful for predicting prognosis in small cell lung cancer. Tohoku J Exp Med. 2015;236(4):297-304. https://doi.org/10.1620/tjem.236.297.

25. Kang MH, Go SI, Song HN, Lee A, Kim SH, Kang JH, Jeong BK, Kang KM, Ling $H$, Lee GW. The prognostic impact of the neutrophil-tolymphocyte ratio in patients with small-cell lung cancer. Br J Cancer. 2014;111(3):452-60. https:// doi.org/10.1038/bjc.2014.317. Epub 2014 Jun 12. PMID: 24921916; PMCID: PMC4119986

26. Käsmann L, Bolm L, Schild SE, Janssen S, Rades D. Neutrophil-to-lymphocyte ratio predicts outcome in limited disease small-cell lung cancer. Lung. 2017; 195(2):217-24

27. Kim EY, Kim N, Kim YS, Seo JY, Park I, Ahn HK, et al. Prognostic significance of modified advanced lung cancer inflammation index (ALI) in patients with small cell lung Cancer_ comparison with original ALI. PLoS One. 2016; 11(10):e0164056. https://doi.org/10.1371/journal.pone eCollection 2016.

28. Kim T, Choi H, Oak CH, Jang TW, Jung MH, Kim J. Correlation between stage of small-cell lung cancer and inflammatory factors. Asian Cardiovasc Thorac Ann. 2019;27(7):554-8. https://doi.org/10.1177/0218492319868407 Epub 2019 Aug 3.

29. Kurishima K, Watanabe H, Ishikawa H, Satoh H, Hizawa N. Modified Glasgow prognostic score in patients with small-cell lung cancer. Mol Clin Oncol. 2017;7(1):121-4. https://doi.org/10.3892/mco.2017.1261 Epub 2017 May 12.

30. Liu D, Huang Y, Li L, Song J, Zhang L, Li W. High neutrophil-to-lymphocyte ratios confer poor prognoses in patients with small cell lung cancer. BMC Cancer. 2017;17(1):882. https://doi.org/10.1186/s12885-017-3893-1.

31. Lohinai Z, Bonanno L, Aksarin A, Pavan A, Megyesfalvi Z, Santa B, et al. Neutrophil-lymphocyte ratio is prognostic in early stage resected small-cell lung cancer. PeerJ. 2019;7:e7232. https://doi.org/10.7717/peerj.232 ecollection 2019.

32. Minami S, Ogata Y, Ihara S, Yamamoto S, Komuta K. Pretreatment Glasgow prognostic score and prognostic nutritional index predict overall survival of patients with advanced small cell lung cancer. Lung Cancer (Auckl). 2017;8: 249-57. https://doi.org/10.2147/LCTT.S142880 eCollection 2017.

33. Pan ZC, Zhang L, Liu C, Huang XB, Shen SF, Lin XY, et al. Cisplatin or carboplatin? Neutrophil to lymphocyte ratio may serve as a useful factor in small cell lung cancer therapy selection. Oncol Lett. 2019;18(2):1513-20.
34. Sakin A, Yasar N, Arici S, Demir C, Geredeli C, Aksaray F, et al. Effect of pretreatment platelet parameters on survival in limited disease small cell lung cancer. Asian Pac J Cancer Prev. 2019;20(6):1879-85. https://doi.org/10. 31557/APJCP.2019.20.6.1879.

35. Sedef AM, Calikusu Z, Bahceci A, Gokcay S, Besen AA, Sumbul AT. Prognostic value of basal neutrophil lymphocyte ratio in patients with extensive stage small cell lung cancer. Cukurova Medical J. 2018;43:285-90.

36. Shao N, Cai Q. High pretreatment neutrophil-lymphocyte ratio predicts recurrence and poor prognosis for combined small cell lung cancer. Clin Transl Oncol. 2015;17(10):772-8. https://doi.org/10.1007/s12094-015-1289-8 Epub 2015 Aug 5.

37. Shen $X B$, Zhang $Y X$, Wang W, Pan YY. The hemoglobin, albumin, lymphocyte, and platelet (HALP) score in patients with small cell lung cancer before firstline treatment with etoposide and progression-free survival. Med Sci Monit. 2019:25:5630-9. https://doi.org/10.12659/MSM.917968.

38. Sonehara K, Tateishi K, Komatsu M, Yamamoto H, Hanaoka M, Kanda S, et al. Modified Glasgow prognostic score as a prognostic factor in patients with extensive disease-small-cell lung cancer: a retrospective study in a single institute. Chemotherapy. 2019:64(3):129-37.

39. Suzuki R, Lin SH, Wei X, Allen PK, Welsh JW, Byers LA, et al. Prognostic significance of pretreatment total lymphocyte count and neutrophil-tolymphocyte ratio in extensive-stage small-cell lung cancer. Radiother Oncol. 2018;126(3):499-505. https://doi.org/10.1016/j.radonc.2017.12.030 Epub 8 Feb 2.

40. Suzuki R, Wei X, Allen PK, Cox JD, Komaki R, Lin SH. Prognostic significance of total lymphocyte count, neutrophil-to-lymphocyte ratio, and platelet-tolymphocyte ratio in limited-stage small-cell lung cancer. Clin Lung Cancer. 2019;20(2):117-23. https://doi.org/10.1016/j.cllc.2018.11.013 Epub Nov 29.

41. Wang C, Jin S, Xu S, Cao S. High Systemic Immune-Inflammation Index (SII) Represents an Unfavorable Prognostic Factor for Small Cell Lung Cancer Treated with Etoposide and Platinum-Based Chemotherapy. Lung. 2020; 198(2):405-14. https://doi.org/10.1007/s00408-020-00333-6. Epub 2020 Feb 3. PMID: 32016563

42. Wang D, Guo D, Shi F, Zhu Y, Li A, Kong L, et al. The predictive effect of the systemic immune-inflammation index for patients with small-cell lung cancer. Future Oncol. 2019;15(29):3367-79. https://doi.org/10.2217/fon-0190288 Epub 2019 Aug 19

43. Wen Q, Meng X, Xie P, Wang S, Sun X, Yu J. Evaluation of factors associated with platinum-sensitivity status and survival in limited-stage small cell lung cancer patients treated with chemoradiotherapy. Oncotarget. 2017:8(46): 81405-18. https://doi.org/10.18632/oncotarget.9073 eCollection 2017 Oct 6.

44. Wu F, Yang S, Tang X, Liu W, Chen H, Gao H. Prognostic value of baseline hemoglobin-to-red blood cell distribution width ratio in small cell lung cancer: a retrospective analysis. Thorac Cancer. 2020;22(10):1759-7714.

45. Xie D, Marks $R$, Zhang $M$, Jiang G, Jatoi A, Garces $Y$ l, et al. Nomograms predict overall survival for patients with small-cell lung cancer incorporating pretreatment peripheral blood markers. J Thorac Oncol. 2015;10(8):1213-20. https://doi.org/10.1097/JTO.0000000000000585.

46. Zhang Q, Qu Y, Liu H, Jia H, Wen F, Pei S, et al. Initial platelet-to-lymphocyte count as prognostic factor in limited-stage small cell lung cancer. Biomark Med. 2019;13(4):249-58. https://doi.org/10.2217/bmm-018-0415 Epub 2019 Jan 9.

47. Zheng Y, Wang L, Zhao W, Dou Y, Lv W, Yang H, et al. Risk factors for brain metastasis in patients with small cell lung cancer without prophylactic cranial irradiation. Strahlenther Onkol. 2018;194(12):1152-62. https://doi.org/ 10.1007/s00066-018-1362-7 Epub 2018 Sep 14.

48. Cao S, Jin S, Shen J, Cao J, Zhang H, Meng Q, et al. Selected patients can benefit more from the management of etoposide and platinum-based chemotherapy and thoracic irradiation-a retrospective analysis of 707 small cell lung cancer patients. Oncotarget. 2017;8(5):8657-69. https://doi.org/10. 18632/oncotarget.4395.

49. Zhou T, Hong SD, Hu ZH, Hou X, Huang Y, Zhao HY, et al. A systemic inflammation-based prognostic scores (mGPS) predicts overall survival of patients with small-cell lung cancer. Tumor Biol. 2015;36(1):337-43.

50. Mirili C, Guney IB, Paydas S, Seydaoglu G, Kapukaya TK, Ogul A, et al. Prognostic significance of neutrophil/lymphocyte ratio (NLR) and correlation with PET-CT metabolic parameters in small cell lung cancer (SCLC). Int J Clin Oncol. 2019;24(2):168-78. https://doi.org/10.1007/s10147-018-1338-8 Epub 2018 Aug 14.

51. Sakin A, Sahin S, Yasar N, Demir C, Arici S, Geredeli C, et al. The relation between hemogram parameters and survival in extensive-stage small cell 
lung cancer. Oncol Res Treat. 2019;42(10):506-15. https://doi.org/10.1159/ 000501595 Epub 2019 Jul 23.

52. Ridker PM, MacFadyen JG, Thuren T, Everett BM, Libby P, Glynn RJ. Effect of interleukin-1 beta inhibition with canakinumab on incident lung cancer in patients with atherosclerosis: exploratory results from a randomised, double-blind, placebo-controlled trial. Lancet. 2017;390(10105):1833-42. https://doi.org/10.1016/S0140-6736(17)32247-X Epub 2017 Aug 27.

53. Harrison P, Pointon JJ, Chapman K, Roddam A, Wordsworth BP. Interleukin-1 promoter region polymorphism role in rheumatoid arthritis: a meta-analysis of IL-1B-511A/G variant reveals association with rheumatoid arthritis. Rheumatology (Oxford). 2008;47(12):1768-70.

54. Jin J, Hu KJ, Zhou YZ, Li WM. Clinical utility of the modified Glasgow prognostic score in lung cancer: a meta-analysis. PLoS One. 2017;12(9): e0184412.

55. Zhu LC, Chen SM, Ma SL, Zhang SR. Glasgow prognostic score predicts prognosis of non-small cell lung cancer: a meta-analysis. Springerplus. 2016; 5:439-444.

56. Lu Y, Jiang J, Ren C. The clinicopathological and prognostic value of the pretreatment neutrophil-to-lymphocyte ratio in small cell lung cancer: a meta-analysis. PLoS One. 2020;15(4):e0230979.

57. Guyatt GH, Oxman AD, Kunz R, Woodcock J, Brozek J, Helfand M, et al. GRADE guidelines: 7. Rating the quality of evidence--inconsistency. J Clin Epidemiol. 2011;64(12):1294-302.

\section{Publisher's Note}

Springer Nature remains neutral with regard to jurisdictional claims in published maps and institutional affiliations.

Ready to submit your research? Choose BMC and benefit from:

- fast, convenient online submission

- thorough peer review by experienced researchers in your field

- rapid publication on acceptance

- support for research data, including large and complex data types

- gold Open Access which fosters wider collaboration and increased citations

- maximum visibility for your research: over $100 \mathrm{M}$ website views per year

At BMC, research is always in progress.

Learn more biomedcentral.com/submissions 